\title{
Overexpression of ZEB2-AS1 IncRNA is associated with poor clinical outcomes in acute myeloid leukemia
}

\author{
XIAOLAN SHI ${ }^{1-3^{*}}$, JIAO LI $^{4 *}$, LIANG MA $^{1}$, LIJUN WEN $^{1}$, QINRONG WANG $^{1}$, HONG YAO $^{1}$, \\ CHANGGENG RUAN ${ }^{1,2}$, DEPEI WU ${ }^{1-3}$, XINYOU ZHANG $^{5}$ and SUNING CHEN ${ }^{1,2}$ \\ ${ }^{1}$ Department of Hematology, Jiangsu Institute of Hematology, Key Laboratory of Thrombosis and \\ Hemostasis of Ministry of Health, The First Affiliated Hospital of Soochow University; \\ ${ }^{2}$ Collaborative Innovation Center of Hematology, ${ }^{3}$ Institute of Blood and Marrow Transplantation, \\ Soochow University, Suzhou, Jiangsu 215006; ${ }^{4}$ Department of Hematology, Yixing People's Hospital of Jiangsu Province, \\ Yixing, Jiangsu 214200; ${ }^{5}$ Department of Hematology, Shenzhen People's Hospital, \\ The Second Clinical Medical College of Jinan University, Shenzhen, Guangdong 518020, P.R. China
}

Received January 10, 2018; Accepted January 28, 2019

DOI: $10.3892 / 01.2019 .10149$

\begin{abstract}
Acute myeloid leukemia (AML) is a fatal hematopoietic malignancy with poor clinical outcomes. To determine whether the expression of the long non-coding (lnc)RNA zinc finger E-box binding homeobox 2 (ZEB2) antisense RNA 1 (ZEB2-AS1) is associated with clinical outcomes, its expression was analyzed in a retrospective cohort of 62 AML and 10 non-malignant cases. The results revealed that the expression of ZEB2-AS1 lncRNA was notably high and closely associated with adverse clinical outcomes in AML cases compared with the non-malignant cases, based on either modified Medical Research Council or European Leukemia Net risk stratification systems. Univariate analyses indicated that patients with a higher expression of ZEB2-AS1 lncRNA had significantly shorter overall survival $(\mathrm{OS})(\mathrm{P}=0.036)$ and disease-free survival $(\mathrm{DFS})$ rates $(\mathrm{P}=0.039)$ compared with patients with a lower expression of ZEB2-AS1 1ncRNA. In addition, patients with a higher expression of ZEB2-AS1 1ncRNA had a significant lower complete remission rate in response to induction by chemotherapy
\end{abstract}

Correspondence to: Professor Suning Chen, Department of Hematology, Jiangsu Institute of Hematology, Key Laboratory of Thrombosis and Hemostasis of Ministry of Health, The First Affiliated Hospital of Soochow University, 188 Shizi Road, Suzhou, Jiangsu 215006, P.R. China

E-mail: chensuning@sina.com

Professor Xinyou Zhang, Department of Hematology, Shenzhen People's Hospital, The Second Clinical Medical College of Jinan University, 1017 Dongmen North Road, Shenzhen, Guangdong 518020, P.R. China

E-mail: zxy0518@live.cn

${ }^{*}$ Contributed equally

Key words: acute myeloid leukemia, long non-coding RNA, zinc finger E-box binding homeobox 2 antisense RNA 1, prognosis compared with patients with a lower expression of ZEB2-AS1 lncRNA $(\mathrm{P}=0.031)$. In cases with low levels of ZEB2-AS1 lncRNA, patients treated with allogenic hematopoietic stem cell transplantation had significantly longer OS and DFS rates compared with that of chemotherapy-treated patients $(\mathrm{P}=0.037$ and $\mathrm{P}=0.049$ respectively). Furthermore, the knockdown of ZEB2-AS1 lncRNA effectively inhibited AML cell invasion and migration, which was closely associated with the downregulation of ZEB2 and upregulation of E-cadherin expression. Collectively, although its independent prognostic value for survival was not rigorously determined, ZEB2-AS1 lncRNA may function as a candidate marker to improve conventional risk stratification systems and the evaluation of therapeutic responses for AML.

\section{Introduction}

Acute myeloid leukemia (AML) is predominantly a fatal hematopoietic malignancy characterized by the clonal proliferation of myeloid blasts with tissue infiltration (1). It may occur at any age, with an incidence of 2-3/100,000 per annum in children $<14$ years old, and $\sim 15 / 100,000$ per annum in adults $>60$ years old globally (2). Despite advances in therapeutic strategies, including intensive chemotherapy and hematopoietic stem cell transplantation (HSCT), the clinical outcome of AML remains poor, particularly in older patients (>60 years old) (3-5). Considering the clonal complexity of AML, there has been increasing interest in improving the prognosis and treatment of AML through the more extensive biological profiling of cytogenetic and molecular tumor heterogeneity (6-10). The Cancer Genome Atlas Research Network has reported that $\sim 70 \%$ of AML cases have mutations in genes encoding epigenetic modifiers $(11,12)$. Notably, novel data has demonstrated that DNA methylation heterogeneity (epialleles) may occur with distinct kinetics and patterns that are likely to affect clinical outcomes. These may be hallmarks of AML and may be independent of the genetic landscape $(13,14)$. Accordingly, differences in epigenetic diversity may function as molecular biomarkers to independently evaluate AML prognosis. 
Long non-coding RNAs (lncRNAs) are a class of RNAs that are $>200$ nucleotides in length (15-17). Gene expression regulated by lncRNAs is regarded as one of the most notable types of epigenetic control $(18,19)$. Recurrent mutations and/or epigenetic alterations in the regulatory non-coding genome may broadly affect lncRNA expression in numerous malignant tumor types, serving as signals for carcinogenesis, in addition to providing information for prognosis and therapeutic options in patients with cancer (20). Notably, the expression of a small subset of lncRNAs, including nuclear paraspeckle assembly transcript 1 , have been strongly associated with treatment response and survival in cytogenetically normal older patients with AML (21). In particular, a range of lncRNAs, including HOXA transcript antisense RNA, myeloid-specific 1 and HOX transcript antisense intergenic RNA myeloid 1 (HOTAIR), may exert pivotal effects not only on hematopoietic stem cells during normal hematopoiesis, but also on the cancer phenotype during the process of leukemogenesis (22-25).

lncRNAs are categorized into antisense, bidirectional, intronic, intergenic and overlapping lncRNAs, based on their chromosomal location $(26,27)$. Antisense lncRNAs are initially transcribed from the opposite strand of a protein-coding counterpart, functioning as fast regulatory mediators in self-regulatory circuits to modulate global and/or specific transcriptional outputs (28-32). Certain antisense lncRNAs, including IGF1R antisense imprinted non-protein coding RNA, are downregulated in patients with high-risk AML, resulting in the promotion of cell growth through long-range chromatin interactions with insulin like growth factor 1 receptor $(33,34)$. Using the Affymetrix Human LncRNA microarray analysis, it was has been demonstrated that the expression of the lncRNA zinc finger E-box binding homeobox 2 (ZEB2) antisense RNA 1 (ZEB2-AS1) is abnormally overexpressed in patients with AML (as yet unpublished). A previous study indicated that a natural antisense transcript, overlapping the $5^{\prime}$ splice site in the intron of the ZEB2 gene, may prevent splicing of the 5'-untranslated region to increase ZEB2 translation and consequently downregulate the expression of E-cadherin, which in turn induces epithelial-mesenchymal transition (EMT) in a tumor (35). However, the prognostic value of ZEB2-AS1 in AML and its function in leukemogenesis remains to be elucidated.

In the present study, 62 de novo patients with AML were retrospectively analyzed to determine if ZEB2-AS1 lncRNA may function as a biomarker to evaluate AML prognosis. Thus, the specific aim of the present study was to assess the association between ZEB2-AS1 lncRNA expression and the clinical features of patients with AML. Additionally, the potential regulation of leukemic phenotypes by ZEB2-AS1 lncRNA was investigated. As such, the clinical and biological importance of ZEB2-AS1 lncRNA were evaluated.

\section{Materials and methods}

Patients and tissue specimens. A total of 62 eligible patients with de novo AML were enrolled retrospectively in the present study. Patients were diagnosed and classified according to the World Health Organization (36) criteria at the First Affiliated Hospital of Soochow University (Jiangsu, China) between May 2007 and June 2014. The clinicopathological characteristics of this cohort are summarized in Table I. Modified
Medical Research Council (MRC) or European Leukemia Net (ELN) recommendations were applied for risk stratification (37-39). The 62 bone marrow specimens were collected from the pretreated patients and were frozen and archived for the following experiments. For comparison, 10 eligible bone marrow specimens were collected from patients without hematopoietic malignancies and were selected as the non-malignant hemotopathy group (Table II). Clinical outcome data were updated as of April 2016. The present research was ethically approved by the Institutional Review Board of the First Affiliated Hospital of Soochow University.

AML cell line. Using the Affymetrix Human LncRNA microarray analysis, it has been demonstrated that ZEB2-AS1 lncRNA is predominantly overexpressed in patients with AML with a karyotype of 11q23. In addition, the expression of ZEB2-AS1 lncRNA in THP-1 cells, also with a karyotype of 11q23, is significantly higher compared with that of other AML cell lines, including AP1060, NB4 and FKH-1 $(\mathrm{P}=0.0020)$. Thus, THP-1 cells were selected for the present study and cultured in RPMI-1640 medium (GE Healthcare Life Sciences, Hyclone, Logan, UT, USA) supplemented with $10 \%$ heat-inactivated fetal bovine serum (FBS; Sigma-Aldrich; Merck KGaA, Darmstadt, Germany) in humidified $37^{\circ} \mathrm{C}$ incubator containing $5 \% \mathrm{CO}_{2}$.

Patient treatment. A total of 39 patients with de novo AML, excluding those diagnosed as the M3 subtype, received front-line induction chemotherapy, including the idarubicin and cytarabine regimen, as follows: Idarubicin $8-12 \mathrm{mg} / \mathrm{m}^{2}$ (days 1-3) and cytarabine $100 \mathrm{mg} / \mathrm{m}^{2}$ (days 1-7); or the daunorubicin and cytarabine regimen, as follows: Daunorubicin $60-90 \mathrm{mg} / \mathrm{m}^{2}$ (days 1-3) and cytarabine $100 \mathrm{mg} / \mathrm{m}^{2}$ (days 1-7). Subsequent to achieving first complete remission (CR, $n=24)$, patients received post-remission therapy of either several consolidation courses $(n=12)$ or allogeneic HSCT (allo-HSCT; $\mathrm{n}=12$ ).

For the treatment of AML with allo-HSCT, patients received an initial conditioning regimen with lomustine ( $250 \mathrm{mg} / \mathrm{m}^{2} /$ day on day -10 ), cytarabine ( 2 or $4 \mathrm{~g} / \mathrm{m}^{2} /$ day; days -9 to -8$)$, busulfan (3.2 $\mathrm{mg} / \mathrm{kg} / \mathrm{day}$; days -7 to -5$)$ and cyclophosphamide ( $1.8 \mathrm{~g} / \mathrm{m}^{2} /$ day; days -4 to -3$)$. Due to advanced patient age or the presence of other comorbidities, patients with poor responses to myeloablative conditioning received a regimen with lomustine $\left(250 \mathrm{mg} / \mathrm{m}^{2} /\right.$ day; day -10), fludarabine $\left(30 \mathrm{mg} / \mathrm{m}^{2}\right.$; days -10 to -6$)$, cytarabine $\left(1.5 \mathrm{~g} / \mathrm{m}^{2} /\right.$ day; days -10 and -6$)$ and busulfan $(3.2 \mathrm{mg} / \mathrm{kg} /$ day; days -5 to -3 ). To effectively prevent graft-versus-host disease (GVHD), cyclosporine $(3 \mathrm{mg} / \mathrm{kg} /$ day) was infused to achieve a target blood concentration between 200-300 ng/ml, starting on day -9 or -1 until patients switched to oral administration. For unrelated or haploidentical transplantation, mycophenolate mofetil (30 mg/kg/day) and rabbit anti-thymocyte globulin ( $2.5 \mathrm{mg} / \mathrm{kg} / \mathrm{day}$; days -5 to -2$)$ were additionally administered to prevent GVHD. In addition, methotrexate was separately administered on days $+1,+3,+6$, and +11 , at doses of $15,10,10$ and $10 \mathrm{mg} / \mathrm{m}^{2}$, respectively.

Cytogenetic and molecular genetic analysis. In the cytogenetic analyses, bone marrow specimens from patients with de novo 
Table I. Clinical, pathological and genetic characteristics of patients with AML.

\begin{tabular}{|c|c|c|c|c|}
\hline \multirow[b]{2}{*}{ Characteristics } & \multirow[b]{2}{*}{ Patients } & \multicolumn{2}{|c|}{ ZEB2-AS1 expression } & \multirow[b]{2}{*}{ P-value } \\
\hline & & Low level & High level & \\
\hline Age (years) & & & & 0.552 \\
\hline Median (range) & $39 \quad(8-80)$ & $39(8-80)$ & $34(14-67)$ & \\
\hline Sex & & & & 0.537 \\
\hline Male & $32(51.6 \%)$ & 24 & 8 & \\
\hline Female & $30(48.4 \%)$ & 25 & 5 & \\
\hline FAB Subtypes & & & & 0.006 \\
\hline M0 & $1(1.6 \%)$ & 0 & 1 & \\
\hline M1 & $1(1.6 \%)$ & 1 & 0 & \\
\hline M2 & $27(43.6 \%)$ & 25 & 2 & \\
\hline M3 & $9(14.5 \%)$ & 9 & 0 & \\
\hline M4 & $10(16.1 \%)$ & 5 & 5 & \\
\hline M5 & $14(22.6 \%)$ & 9 & 5 & \\
\hline Karyotype & & & & $<0.001$ \\
\hline Normal karyotype & $16(25.8 \%)$ & 14 & 2 & \\
\hline $\mathrm{t}(15 ; 17)$ & $9(14.5 \%)$ & 9 & 0 & \\
\hline $\mathrm{t}(8 ; 21)$ & $13(21.0 \%)$ & 12 & 1 & \\
\hline inv (16) & $7(11.3 \%)$ & 5 & 2 & \\
\hline $\mathrm{t}(6 ; 9)$ & $5(8.0 \%)$ & 5 & 0 & \\
\hline $11 \mathrm{q} 23$ & $8(12.9 \%)$ & 4 & 4 & \\
\hline Complex karyotype & $4(6.5 \%)$ & 0 & 4 & \\
\hline White blood cell (x1099/1; non-M3) & & & & 0.046 \\
\hline Median (range) & $24.3(1.0-190.5)$ & $13.5(1.0-140.2)$ & $52.1(1.3-190.3)$ & \\
\hline Hemoglobin (g/l; non-M3) & & & & 0.372 \\
\hline Median (range) & $84.0(37.0-149.0)$ & $84.0(37.0-149.0)$ & $88.0(38.0-116.0)$ & \\
\hline Platelets (x109/1; non-M3) & & & & 0.044 \\
\hline Median (range) & $40(8.0-414.0)$ & $31(8-414)$ & $71.5(20-410)$ & \\
\hline Blasts in bone marrow (\%; non-M3) & & & & 0.569 \\
\hline Median (range) & $56.5(20.5-98.0)$ & $57(20.5-95.5)$ & $56.5(25.0-98.0)$ & \\
\hline Mutated gene (non-M3) & & & & 0.474 \\
\hline Negative & 15 & 12 & 3 & \\
\hline CEBPA & 2 & 2 & 0 & \\
\hline NPM1 & 1 & 1 & 0 & \\
\hline FLT3-ITD & 1 & 1 & 0 & \\
\hline FLT3-TKD & 1 & 1 & 0 & \\
\hline DNMT3A & 1 & 1 & 0 & \\
\hline C-kit & 4 & 1 & 3 & \\
\hline C-kit/CEBPA & 2 & 2 & 0 & \\
\hline NPM1/FLT3-TKD & 1 & 1 & 0 & \\
\hline FLT3-ITD/CEBPA & 1 & 1 & 0 & \\
\hline NPM1/DNMT3A & 1 & 1 & 0 & \\
\hline DNMT3A/NPM1/FLT3-ITD & 2 & 1 & 1 & \\
\hline Modified MRC risk stratification & & & & 0.002 \\
\hline Favorable & $29(46.8 \%)$ & 26 & 3 & \\
\hline Intermediate & $28(45.1 \%)$ & 22 & 6 & \\
\hline Adverse & $5(8.1 \%)$ & 1 & 4 & \\
\hline ELN risk stratification (non-M3) & & & & 0.028 \\
\hline Favorable & 27 & 24 & 3 & \\
\hline Intermediate I and II & 13 & 8 & 5 & \\
\hline Adverse & 10 & 5 & 5 & \\
\hline
\end{tabular}


Table I. Continued.

\begin{tabular}{|c|c|c|c|c|}
\hline \multirow[b]{2}{*}{ Characteristics } & \multirow[b]{2}{*}{ Patients } & \multicolumn{2}{|c|}{ ZEB2-AS1 expression } & \multirow[b]{2}{*}{ P-value } \\
\hline & & Low level & High level & \\
\hline Recovery from induction chemotherapy (non-M3) & & & & 0.031 \\
\hline $\mathrm{CR}$ & 24 & 21 & 3 & \\
\hline Non-CR & 15 & 7 & 8 & \\
\hline
\end{tabular}

Table II. Characteristics of 10 non-malignant hemotopathy cases.

\begin{tabular}{lccc}
\hline Sex & Number & Age & Number \\
\hline Male & 3 & $\geq 60$ & 2 \\
Female & 7 & $<60$ & 8 \\
WBC & $5.585(2.6-9.18) \times 10^{9} / 1$ & Diagnosed & Number \\
HGB & $74.5(57-156) \mathrm{g} / 1$ & IDA & 8 \\
PLT & $281(10-324) \times 10^{9} / 1$ & ITP & 2 \\
\hline
\end{tabular}

WBC, white blood cell count; HGB, hemoglobin; PLT, platelet count.

AML were processed in standard un-stimulated cultures for $24 \mathrm{~h}$. With standard techniques of ISCN 2016 (40) for chromosome R-banding and fluorescence in situ hybridization, the different karyotypes in patients with AML were routinely determined. If available, at least 20 metaphases were analyzed for every bone marrow sample. For analyzing mutations in patients with de novo AML, a Purelink ${ }^{\mathrm{TM}}$ Genomic DNA mini kit (Invitrogen; Thermo Fisher Scientific, Inc., Waltham, MA, USA) was used to extract genomic DNA from the 62 patients' bone marrow mononuclear cells, according to the manufacturer's protocol. The coding regions of mutated genes were either partially or entirely amplified using a polymerase chain reaction (PCR) in order to identify these mutations. The genomic DNA was extracted from the 62 patients' bone marrow mononuclear cells. The thermo cycling conditions were as follows $95^{\circ} \mathrm{C} 5 \mathrm{~min}$, total 35 cycles of $95^{\circ} \mathrm{C} 30 \mathrm{sec}$ and $58^{\circ} \mathrm{C} 30 \mathrm{sec}$ and $72^{\circ} \mathrm{C} 1 \mathrm{~min}$, then $72^{\circ} \mathrm{C} 10 \mathrm{~min}$. Direct bidirectional DNA sequencing was subsequently performed. In the present study, a range of acute leukemia-associated mutations were evaluated, including fms related tyrosine kinase 3 (FLT3)-internal tandem duplication (FLT3-ITD, forward, 5'-CAATTTAGGTATGAAAGCC-3' and reverse, 5'-GTA CCTTTCAGCATTTTGAC-3'), DNA methyltransferase $3 \alpha$ (DNMT3A, forward, 5'-CTGCTGTGTGGTTAGACG-3' and reverse, 5'-TATTTCCGCCTCTGTGGTTT-3'), FLT3-tyrosine kinase domain (FLT3-TKD, forward, 5'-CCAGGAACGTGC TTGTCA-3' and reverse, 5'-TCAAAAATGCACCACAGT GAG-3'), C-kit (forward, 5'-CTCCCTGAAAGCAGAAAC-3' and reverse, 5'-CAGAAAGATAACACCAAAATAG-3'),
CCAAT enhancer binding protein $\alpha$ (CEBPA, forward, 5'-GGC GAGCAGGGTCTCCGGGT-3' and reverse, 5'-TGTGCT GGAACAGGTCGGCCA-3') and nucleophosmin 1 (NPM1, forward, 5'-TTAACTCTCTGGTGGTAGAATGAA-3' and reverse, 5'-TGTTACAGAAATGAAATAAGACGG-3').

$R N A$ extraction and reverse transcription-quantitative (RT-q) $P C R$. Total RNA was extracted from patient bone marrow mononuclear cells using TRIzol (Invitrogen; Thermo Fisher Scientific, Inc.). RT and first strand cDNA synthesis was subsequently performed using MMLV-RT reverse transcriptase (Promega Corporation, Madison, WI, USA $37^{\circ} \mathrm{C} 60 \mathrm{~min}$, $95^{\circ} \mathrm{C} 5 \mathrm{~min}$ ). RT-qPCR analysis was employed to detect levels of ZEB2-AS1. GAPDH was used as an internal reference gene. The primer sequences used were as follows: ZEB2-AS1 forward, 5'-GGCTGGATAGCAAAGGAC-3' and reverse, 5'-ACACTCTTGGCGAGGT-3'; ZEB2 forward, 5'-GTCCAT GCGAACTGCCATCT-3' and reverse, 5'-ATCTGTCCCTGG CTTGTGTG-3'; E-cadherin forward, 5'-TGCCCAGAAAAT GAAAAAGG-3' and reverse, 5'-GTGTATGTGGCAATG CGTTC-3'; GAPDH forward, 5'-CAAGGTCATCCATGA CAACTTTG-3', and reverse, 5'-GTCCACCACCCTGTT GCTGTAG-3'. SYBR Green (Taraka, Japan) RT-qPCR was performed and the relative threshold cycle value normalized to the reference GAPDH gene was obtained (ABI 7500; Thermo Fisher Scientific, Inc.) The thermo cycling conditions were as follows $50^{\circ} \mathrm{C} 2 \mathrm{~min}, 95^{\circ} \mathrm{C} 10 \mathrm{~min}, 95^{\circ} \mathrm{C} 15 \mathrm{sec}, 60^{\circ} \mathrm{C} 1 \mathrm{~min}$, for a total of 40 cycles. Following this, $2^{-\Delta \Delta \mathrm{Cq}}$ was calculated to determine relative abundance of target gene expression between the groups (41).

RNA interference. Gene-specific small interfering RNAs (siRNAs) against ZEB2-AS1 (siZEB2-AS1; sense, 5'-CAC CUUUGGUUACCUGAAUTT-3' and antisense, 5'-AUUCAG GUAACCAAAGGUGTT-3') and negative control (NC) siRNA (sense, 5'-UUCUCCGAACGUGUCACGUTT-3' and antisense, 5'-ACGUGACACGUUCGGAGAATT-3') were commercially designed (Shanghai GenePharma Co., Ltd., Shanghai, China). On the day of transfection, THP-1 cells were plated at a low density of $2 \times 10^{5}$ on the culture vessel (Corning, Corning, NY, USA) and subsequently transfected with $40 \mathrm{nM}$ on-target siRNA using Lipofectamine ${ }^{\mathrm{TM}} 2000$ (Invitrogen; Thermo Fisher Scientific, Inc.) according to the manufacturer's protocol cells were incubated with siRNA for $24-48 \mathrm{~h}$. NC siRNA was 
used as a transfection control in all experiments. Each experiment was independently repeated at least three times.

Analyses of biological phenotype. To analyze cell migration, $1 \times 10^{5}$ THP-1 cells (siZEB2-AS1 and NC groups) were plated into the upper chamber of Transwell cell culture inserts (24-well; pore size, $8 \mu \mathrm{m}$; Corning) in serum-free DMEM media (GE Healthcare Life Sciences). The lower chamber medium was supplemented with $20 \%$ FBS. To assess cell invasion, $1 \times 10^{5}$ THP-1 cells (siZEB2-AS1 and NC groups) were seeded into the upper chamber of Transwell cell culture inserts (24-well; pore size, $8 \mu \mathrm{m}$; Corning) coated with Matrigel. The lower chamber medium contained 20\% FBS. Following incubation at $37^{\circ} \mathrm{C}$ for $24 \mathrm{~h}$, the upper layer of THP-1 cells was removed with cotton wool, and THP-1 cells on the lower surface were fixed with $95 \%$ ethanol for $20 \mathrm{~min}$ in room temperature. Invaded or migrated cells were subsequently stained with $0.1 \%$ crystal violet for $30 \mathrm{~min}$ at $37^{\circ} \mathrm{C}$ and observed under an IX71 inverted microscope at x200 magnification (Olympus Corporation, Tokyo, Japan). Five microscopic fields were counted per insert. Triplicate inserts were used for each individual experiment, and each experiment was independently repeated at least three times.

To assess cell proliferation, THP-1 cell lines (siZEB2-AS1 and NC groups) were seeded onto 96-well cell culture cluster plates (Corning) at a concentration of $5 \times 10^{4}$ cells/well in volumes of $100 \mu \mathrm{l}$. A total of $10 \mu \mathrm{l}$ Cell Counting Kit-8 reagent (Dojindo, Kumamoto, Japan) was added to each well at the indicated time points $(24,48,72,96 \mathrm{~h}, 5,7$ days) and incubated in the dark at $37^{\circ} \mathrm{C}$ for a further $4 \mathrm{~h}$. The absorbency was subsequently measured at the wavelength of $450 \mathrm{~nm}$ with the Varioskan Flash Multimode Reader (Thermo Fisher Scientific, Inc.). Each experiment was independently repeated at least three times.

To detect cell apoptosis, 10X binding buffer (eBioscience; Thermo Fisher Scientific, Inc.) was initially diluted to $1 \mathrm{X}$ using distilled water ( $1 \mathrm{ml} \mathrm{10X}$ binding buffer $+9 \mathrm{ml}$ distilled water). Cells were washed once in phosphate buffered saline and once in $1 \mathrm{X}$ binding buffer, prior to cell resuspension in $1 \mathrm{X}$ binding buffer to $1-5 \times 10^{6} / \mathrm{ml}$. A total of $5 \mu$ l fluorochrome-conjugated Annexin V (eBioscience; Thermo Fisher Scientific, Inc.) was added to $100 \mu \mathrm{l}$ cell suspension and incubated for $10-15 \mathrm{~min}$ at room temperature. Cells were washed in $1 \mathrm{X}$ binding buffer and resuspended in $200 \mu \mathrm{l} 1 \mathrm{X}$ binding buffer. A total of $5 \mu \mathrm{l}$ 7-Aminoactinomycin D viability staining solution $\left(2-8^{\circ} \mathrm{C}\right)$ (eBioscience; Thermo Fisher Scientific, Inc.) was added (stained within $4 \mathrm{~h}$ and stored at $2-8^{\circ} \mathrm{C}$ in the dark). Cells were analyzed using 5-color flow cytometry (type FC500, Beckman Coulter company, Fullerton, CA, USA). Each experiment was independently repeated at least three times.

Statistical analysis. All continuous data were expressed as the mean \pm standard error of the mean. One-way analysis of variance with Bonferroni's correction post-hoc test for multiple comparisons were performed. Survival probabilities were estimated using the Kaplan-Meier method and differences between survival distributions were evaluated using the log-rank test. Cox's proportional hazards model was applied to estimate the hazard ratio for disease-free survival (DFS) and overall survival (OS) rates. For all analyses, the P-values were two-tailed and the confidence interval was 95\%. $\mathrm{P}<0.05$ was considered to indicate a statistically significant difference. SPSS statistical software version 18 (SPSS, Inc., Chicago, IL, USA) was used to perform all statistical analyses.

\section{Results}

Clinical, cytogenetic and molecular features of patients with $A M L$. The clinical features of the 62 AML cases enrolled in the present study were summarized in Table I. Based on the modified MRC classification, patients were categorized into a favorable risk group $(n=29)$, an intermediate risk group $(n=28)$ and an adverse risk group $(n=5)$. According to ELN recommendations (12 cases missed the required mutation data and were not classified), patients were categorized into a favorable risk group $(n=27)$, an intermediate I/II risk group $(n=13)$ and an adverse risk group ( $n=10$; Table I). The respective values of median OS and DFS rates, regarding different risk tiers and treatment approaches, were summarized in Table III.

Expression of ZEB2-AS1 lncRNA in patients with AML. Using the Affymetrix Human LncRNA microarray, dozens of abnormally expressed lncRNAs were identified in patients with AML. ZEB2-AS1 lncRNA was identified to be substantially overexpressed in patients with AML with a karyotype of 11q23 when compared with karyotypes such as $t(15 ; 17), t(8 ; 21)$ and inv (16). Therefore, the ZEB-AS1 lncRNA was selected for further analysis in the following experiments. To further confirm the microarray results, RT-qPCR was performed; the results revealed that the expression levels of ZEB-AS1 lncRNA in the AML group $(n=62)$ were significantly higher compared with that of the patients with non-malignant hemotopathy $(n=10$; $\mathrm{P}<0.001$; Fig. 1A) and healthy volunteers ( $\mathrm{n}=4 ; \mathrm{P}=0.010$; Fig. 1A). In addition, the expression levels of ZEB-AS1 lncRNA were positively associated with increasing AML risk levels, according to modified MRC and ELN recommendations (Fig. 1B and C). Furthermore, the expression levels of ZEB-AS1 lncRNA were significantly higher in patients with AML that had not achieved CR $(n=15)$ compared with those who had $(n=24)$ subsequent to the first induction of chemotherapy ( $\mathrm{P}=0.042$; Fig. 1D).

ZEB2-AS1 IncRNA expression and AML clinical outcomes. In the present study, ZEB2-AS1 lncRNA expression levels greater than the 75th percentile were considered to be high expression levels whereas those below were considered to be low, respectively. Overall, 42 AML cases had available survival data. As presented in Fig. 2, Kaplan-Meier survival plots indicated that patients with AML with high ZEB2-AS1 lncRNA expression $(n=6)$ had significantly shorter OS (3-year OS, 0.0 vs. $68.2 \% ; \mathrm{P}=0.036)$ and lower DFS rates (3-year DFS, 25.0 vs. 69.8\%; $\mathrm{P}=0.039$ ) compared with that of the low expression subgroup $(n=36)$. Additionally, according to the modified MRC risk stratification, in the favorable/intermediate risk group, patients with AML with low ZEB2-AS1 lncRNA expression $(n=36)$ had significantly longer OS (3-year OS, 68.2 vs. 33.3\%; $\mathrm{P}=0.026$ ) and higher DFS rates (3-year DFS, 69.8 vs. 33.3\%; $\mathrm{P}=0.038$ ) compared with that of the high expression subgroup ( $\mathrm{n}=3$; Fig. 3A). Furthermore, according to the ELN risk stratification, in the favorable/intermediate I/II risk groups, patients with AML with low ZEB2-AS1 1ncRNA expression $(\mathrm{n}=23)$ had significantly longer OS (3-year OS, 69.9 vs. 50.0\%; $\mathrm{P}=0.034)$ and higher DFS rates (3-year DFS, 
Table III. Clinical outcomes of patients with AML.

\begin{tabular}{|c|c|c|c|c|}
\hline \multirow[b]{2}{*}{ Groups } & \multicolumn{2}{|c|}{ OS rate (months) } & \multicolumn{2}{|c|}{ DFS rate (months) } \\
\hline & Median $(95 \% \mathrm{CI})$ & P-value & Median $(95 \% \mathrm{CI})$ & P-value \\
\hline Age (years) & & 0.187 & & 0.199 \\
\hline$<60$ & $35.0(30.33-43.89)$ & & $29.0(27.42-41.72)$ & \\
\hline$\geq 60$ & $27.0(16.47-42.73)$ & & $24.0(12.98-41.82)$ & \\
\hline Sex & & 0.254 & & 0.246 \\
\hline Male & $25.0(23.99-42.01)$ & & $24.0(20.66-39.97)$ & \\
\hline Female & $40.0(30.15-47.59)$ & & $39.0(27.44-45.60)$ & \\
\hline White blood cell (x109/1; non-M3) & & 0.443 & & 0.403 \\
\hline$<$ Median & $35.0(27.74-51.39)$ & & $28.0(24.48-48.77)$ & \\
\hline$\geq$ Median & $25.0(21.86-41.55)$ & & $24.0(17.79-39.27)$ & \\
\hline Hemoglobin (g/1; non-M3) & & 0.988 & & 0.924 \\
\hline$<$ Median & $28.0(25.22-39.14)$ & & $27.0(21.53-6.35)$ & \\
\hline$\geq$ Median & $39.5(25.00-53.12)$ & & $38.5(21.40-50.98)$ & \\
\hline Platelets (x109/1; non-M3) & & 0.199 & & 0.262 \\
\hline$<$ Median & $40.0(30.38-47.31)$ & & $39.0(26.65-44.62)$ & \\
\hline$\geq$ Median & $23.0(16.93-45.07)$ & & $21.0(13.29-43.00)$ & \\
\hline Blasts in bone marrow (\%; non-M3) & & 0.590 & & 0.512 \\
\hline$<$ Median & $33.0(24.59-49.41)$ & & $25.5(20.41-46.34)$ & \\
\hline$\geq$ Median & $32.0(24.53-43.71)$ & & $29.0(21.31-41.87)$ & \\
\hline MRC risk stratification & & 0.005 & & 0.003 \\
\hline Favorable & $38.0(32.36-45.91)$ & & $29.0(30.32-44.20)$ & \\
\hline Intermediate & $27.0(20.92-45.32)$ & & $24.0(17.24-43.11)$ & \\
\hline Adverse & $29.0(12.02-45.98)$ & & $23.0(5.13-40.88)$ & \\
\hline ELN risk stratification (non-M3) & & 0.003 & & 0.003 \\
\hline Favorable & $40.0(32.29-53.18)$ & & $39.0(29.52-51.01)$ & \\
\hline Intermediate $\mathrm{I} / \mathrm{II}$ & $25.0(15.25-37.35)$ & & $22.0(10.43-35.37)$ & \\
\hline Adverse & $19.5(11.51-36.99)$ & & $15.5(6.1732 .33)$ & \\
\hline Treatment approaches (non-M3) & & 0.113 & & 0.166 \\
\hline Chemotherapy & $29.5(23.15-41.05)$ & & $26.5(19.84-38.56)$ & \\
\hline Allo-HSCT & $31.5(23.80-47.77)$ & & $25.5(19.23-44.91)$ & \\
\hline ZEB2-AS1 level & & 0.036 & & 0.039 \\
\hline Low level & $36.5(30.98-44.40)$ & & $31.5(28.55-42.50)$ & \\
\hline High level & $22.0(10.55-44.12)$ & & $20.0(3.98-41.74)$ & \\
\hline
\end{tabular}

AML, acute myeloid leukemia; OS, overall survival; DFS, disease-free survival; MRC, Medical Research Council; ELN, European Leukemia Net; HSCT, hematopoietic stem cell transplantation; CI, confidence interval; ZEB2-AS1, zinc finger E-box binding homeobox 2 antisense RNA 1.

71.1 vs. $50.0 \%$; $\mathrm{P}=0.034$ ) compared with that of the high expression subgroup (n=2; Fig. 3B). The expression levels of ZEB2-AS1 IncRNA in the adverse risk group were all comparatively high.

In the multivariate analyses, subsequent to controlling for confounding variables in modified MRC (favorable/intermediate vs. adverse) and ELN risk stratification (favorable/intermediate I/II vs. adverse) groups, high ZEB2-AS1 lncRNA expression was determined to not be significantly associated with adverse patient outcomes, including reduced OS $(\mathrm{P}=0.976)$ and $\mathrm{DFS}$ rates $(\mathrm{P}=0.725$; Table IV) compared with the low ZEB2-AS1 1ncRNA expression group.
ZEB2-AS1 lncRNA expression and AML treatment response. Patients with AML with high ZEB2-AS1 lncRNA expression, excluding those classed as the M3 subtype, had a significantly lower $\mathrm{CR}$ rate compared with that of the low expression subgroup ( $\mathrm{P}=0.031$; Table I). However, differences between the OS and DFS rates in the consolidation chemotherapy $(n=10)$ and allo-HSCT treatment groups $(n=14)$ were not significantly different ( $\mathrm{P}>0.05$; Table III). Using the stratification method to control for confounding variables, as presented in Fig. 4, it was demonstrated that patients with a low ZEB2-AS1 IncRNA expression within the allo-HSCT 
A

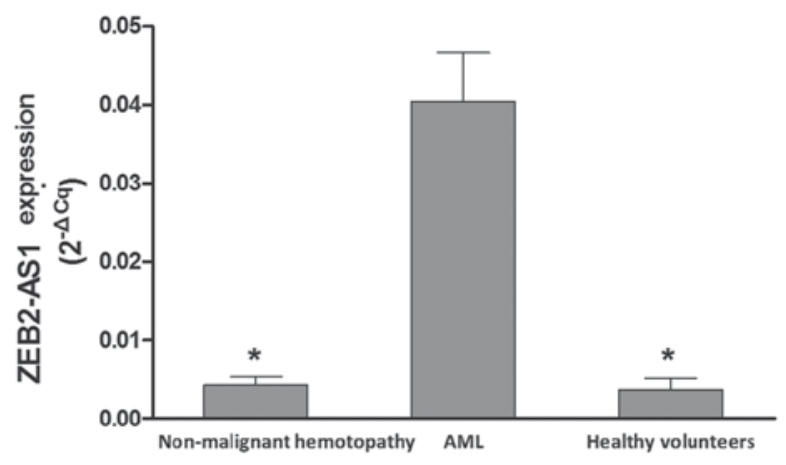

C

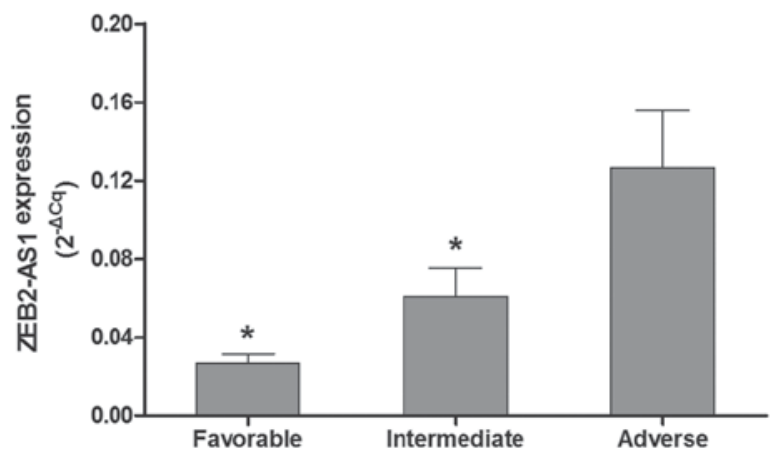

B

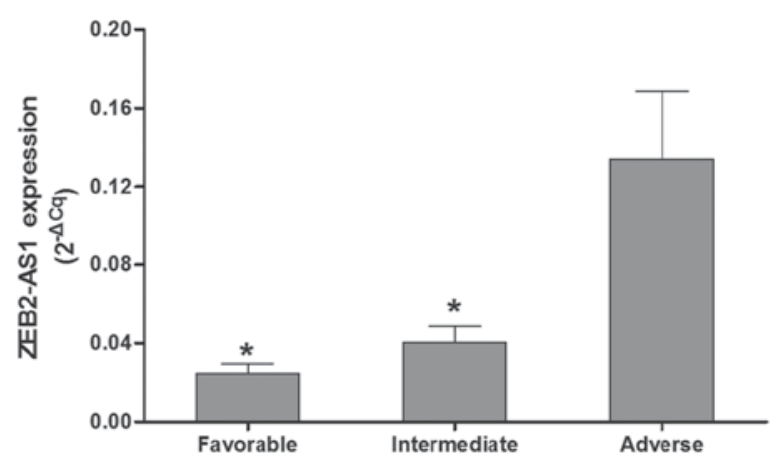

D

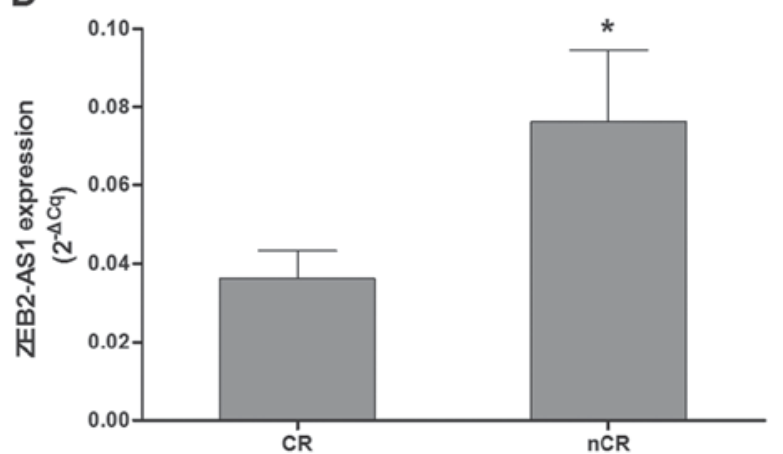

Figure 1. Association of the expression levels of ZEB2-AS1 lncRNA with different clinical features in patients with AML. (A) Expression levels of ZEB2-AS1 lncRNA in patients with AML were significant higher compared with that of non-malignant hemotopathy patients and healthy volunteers ( $\mathrm{P}<0.05$ ). (B) According to the modified Medical Research Council risk stratification systems, the expression levels of ZEB2-AS1 lncRNA exhibited a significant difference between favorable, intermediate and adverse risk groups of patients with AML ( $\mathrm{P}<0.05)$. (C) According to the European Leukemia Net risk stratification systems, the expression levels of ZEB2-AS1 lncRNA demonstrated a significant difference between favorable, intermediate and adverse risk groups of patients with AML ( $\mathrm{P}<0.05)$. (D) Expression levels of ZEB2-AS1 lncRNA were significantly higher in patients who had not achieved CR compared with that of patients who had achieved CR subsequent to the first induction of chemotherapy ( $\mathrm{P}<0.05)$. Values are the mean \pm the standard error of the mean. ZEB2-AS1, zinc finger E-box binding homeobox 2 antisense RNA 1; lncRNA, long non-coding RNA; AML, acute myeloid leukemia; CR, complete remission.
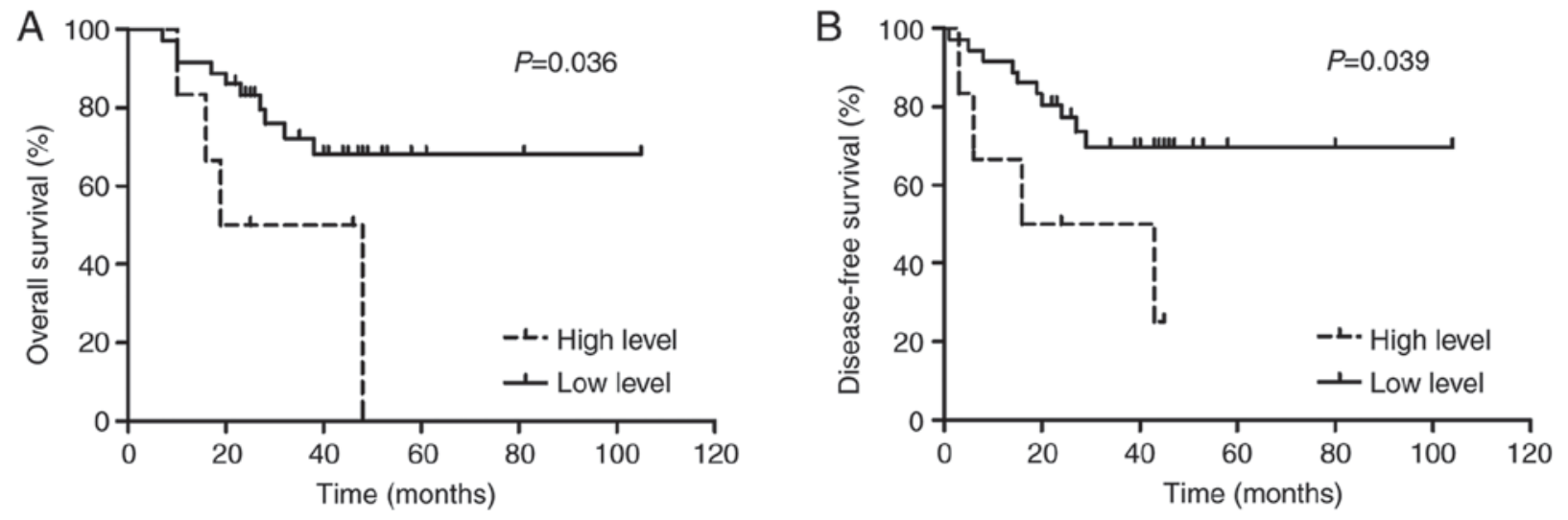

Figure 2. Comparison of OS and DFS rates for patients with AML with different expression levels of ZEB2-AS1 lncRNA. The cut-off value of ZEB2-AS1 IncRNA was the 75th percentile. Expression levels greater or less than the 75th percentile were tentatively considered as the high or low expression groups, respectively. Patients with AML with a high expression of ZEB2-AS1 1ncRNA demonstrated a significantly shorter (A) OS (3-year OS, 0.0 vs. 68.2\%; $\mathrm{P}=0.036$ ) and (B) DFS (3-year DFS, 25.0 vs. 69.8\%; $\mathrm{P}=0.039$ ) compared with that of the low expression of ZEB2-AS1 lncRNA group. OS, overall survival; DFS, disease-free survival; AML, acute myeloid leukemia; ZEB2-AS1, zinc finger E-box binding homeobox 2 antisense RNA 1; lncRNA, long non-coding RNA.

treatment group $(n=11)$ had significantly longer OS (3-year OS, 75.8 vs. $28.6 \%$; $\mathrm{P}=0.037$ ) and DFS rates (3-year DFS, 81.8 vs. $28.6 \%$; $\mathrm{P}=0.049)$ compared with that of the chemotherapy group $(n=7)$.
ZEB2-AS1 IncRNA expression and AML cell biological phenotype. Knockdown of ZEB2-AS1 lncRNA by siRNA in THP-1 cells significantly inhibited the mRNA expression levels of ZEB2 $(n=4 ; P<0.05)$ and stimulated the mRNA 

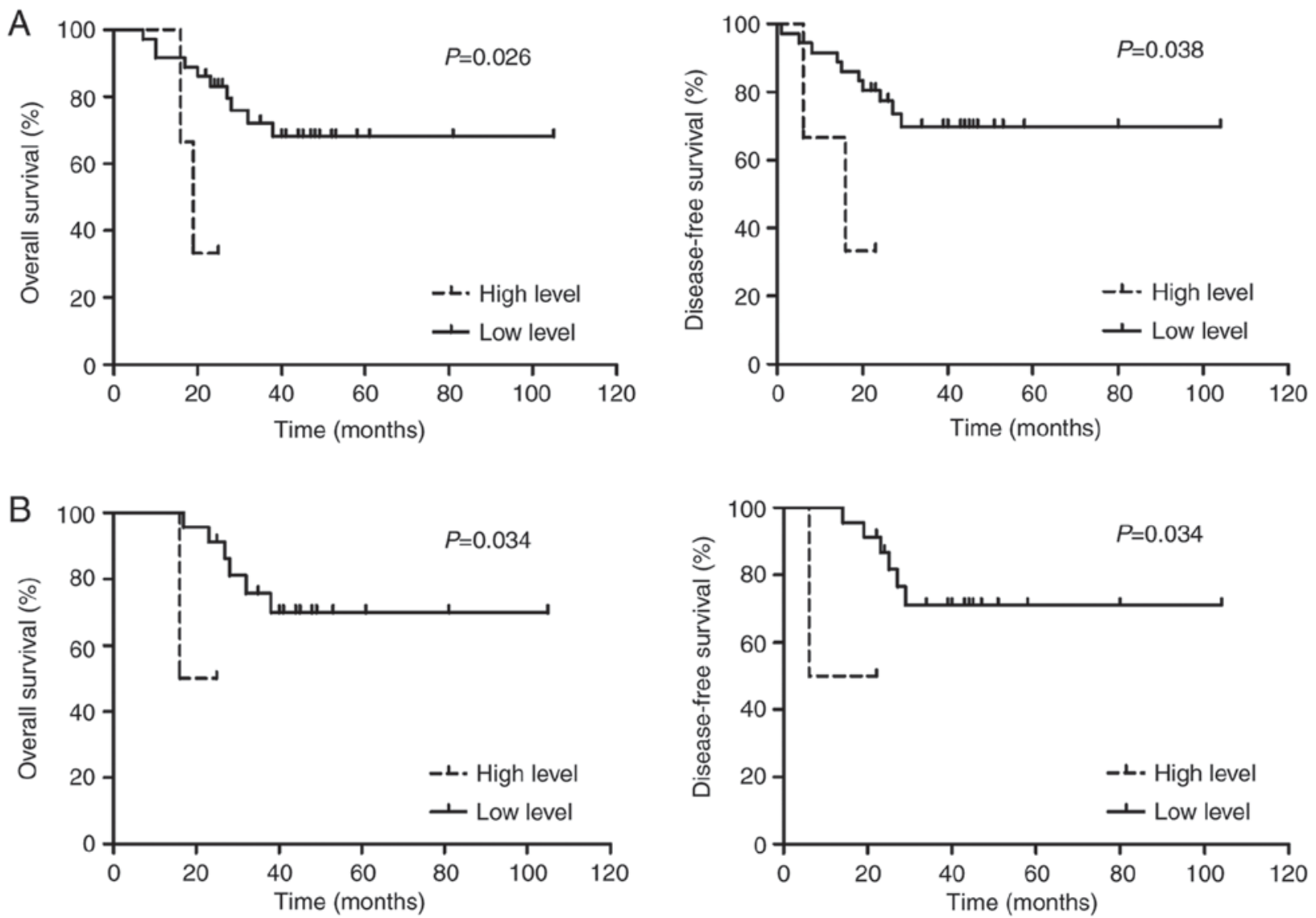

Figure 3. Comparison of OS and DFS rates for patients with AML in favorable/intermediate risk groups. (A) According to the modified Medical Research Council risk stratification recommendation, in the favorable/intermediate risk group, patients with AML with a high expression of ZEB2-AS1 lncRNA exhibited significantly shorter OS (3-year OS, 33.3 vs. 68.2\%; $\mathrm{P}=0.026$ ) and DFS (3-year DFS, 33.3 vs. 69.8\%; $\mathrm{P}=0.038$ ) rates compared with that of the low expression of ZEB2-AS1 lncRNA group. (B) According to the European Leukemia Net risk stratification recommendation, in the favorable/intermediate risk group, patients with AML with a high expression of ZEB2-AS1 lncRNA demonstrated significantly shorter OS (3-year OS, 50.0 vs. $69.9 \%$; $\mathrm{P}=0.034$ ) and DFS (3-year DFS, 50.0 vs. 71.1\%; P=0.034) rates compared with that of the low expression of ZEB2-AS1 lncRNA group. OS, overall survival; DFS, disease-free survival; AML, acute myeloid leukemia; ZEB2-AS1, zinc finger E-box binding homeobox 2 antisense RNA 1; lncRNA, long non-coding RNA.
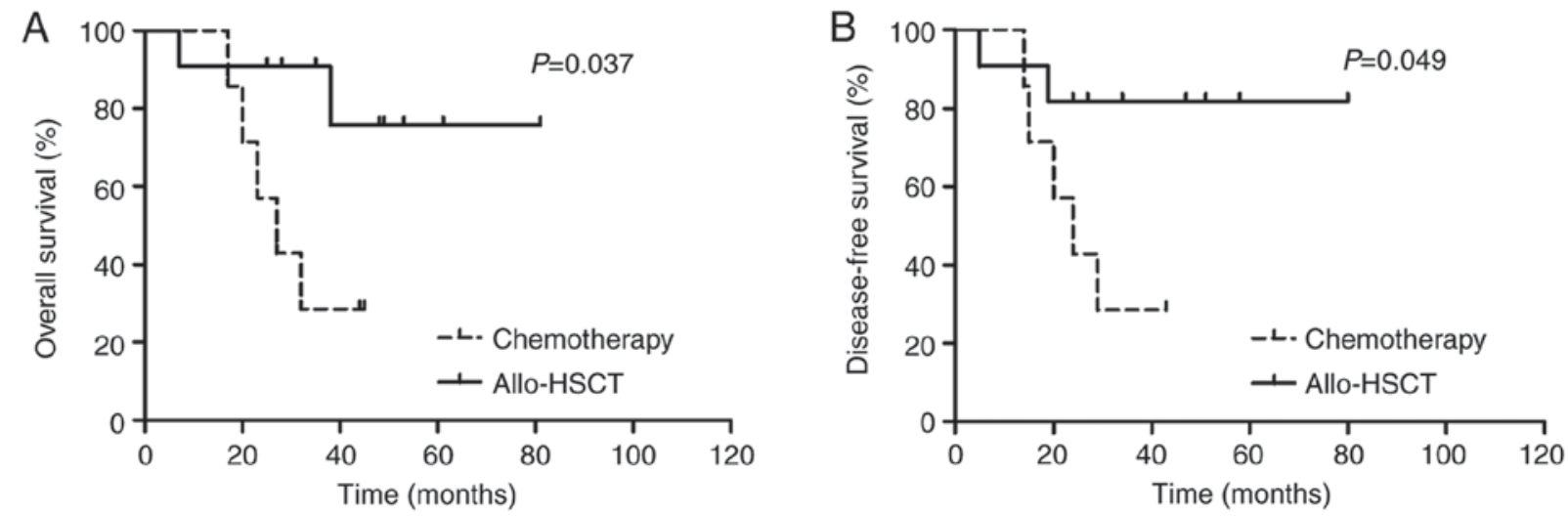

Figure 4. Comparison of OS and DFS rates for patients with AML with a low expression of ZEB2 antisense RNA 1 long non-coding RNA treated using different treatment strategies. Patients with AML receiving allo-HSCT exhibited significant longer (A) OS (3-year OS, 75.8 vs. 28.6\%; P=0.037) and (B) DFS (3-year DFS, 81.8 vs. $28.6 \%$; $\mathrm{P}=0.049$ ) rates compared with that of the chemotherapy treatment group. OS, overall survival; DFS, disease-free survival; AML, acute myeloid leukemia; allo-HSCT, allogenic hematopoietic stem cell transplantation.

expression levels of E-cadherin $(n=4 ; P<0.05)$ compared with the sham and vehicle groups (Fig. 5A and B). As presented in Fig. $6 \mathrm{~A}$ and $\mathrm{B}$, the migration $(\mathrm{n}=4)$ and invasion $(n=4)$ of THP-1 cells, respectively, were significantly inhibited by the knockdown of ZEB2-AS1 lncRNA compared with the sham and vehicle groups $(\mathrm{P}<0.05)$. THP-1 cell proliferation $(n=4)$ and apoptosis $(n=4)$ were not significantly different following the knockdown of ZEB2-AS1 lncRNA compared with the sham and vehicle groups (Fig. 7A and B). 
A

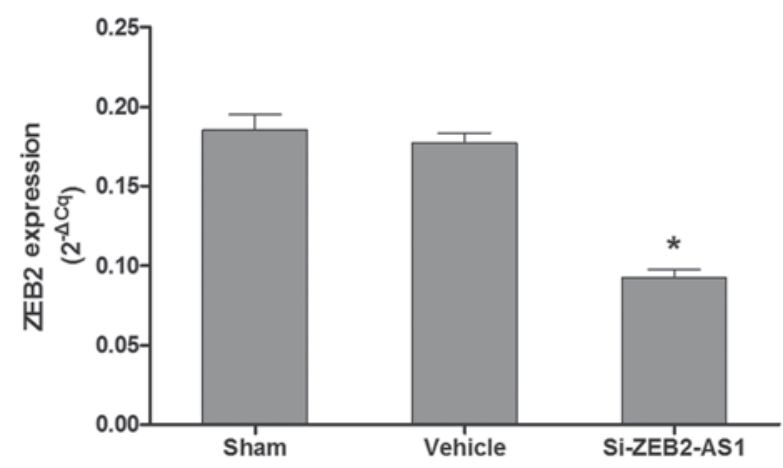

B

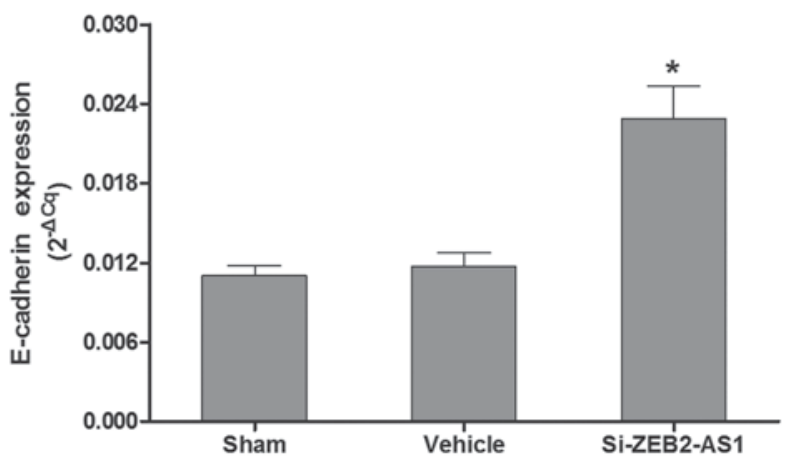

Figure 5. Effects of the downregulation of ZEB2-AS1 1ncRNA on the mRNA expression levels of ZEB2 and E-cadherin in THP-1 cells. Subsequent to the knockdown of ZEB2-AS1 lncRNA in THP-1 cells, the mRNA expression levels of (A) ZEB2 were significantly decreased and (B) E-cadherin were significantly increased. ${ }^{*} \mathrm{P}<0.05$ vs. Sham and vehicle groups. Values are the mean \pm standard error of the mean. ZEB2-AS1, zinc finger E-box binding homeobox 2 antisense RNA 1; lncRNA, long non-coding RNA; si-, small interfering RNA.
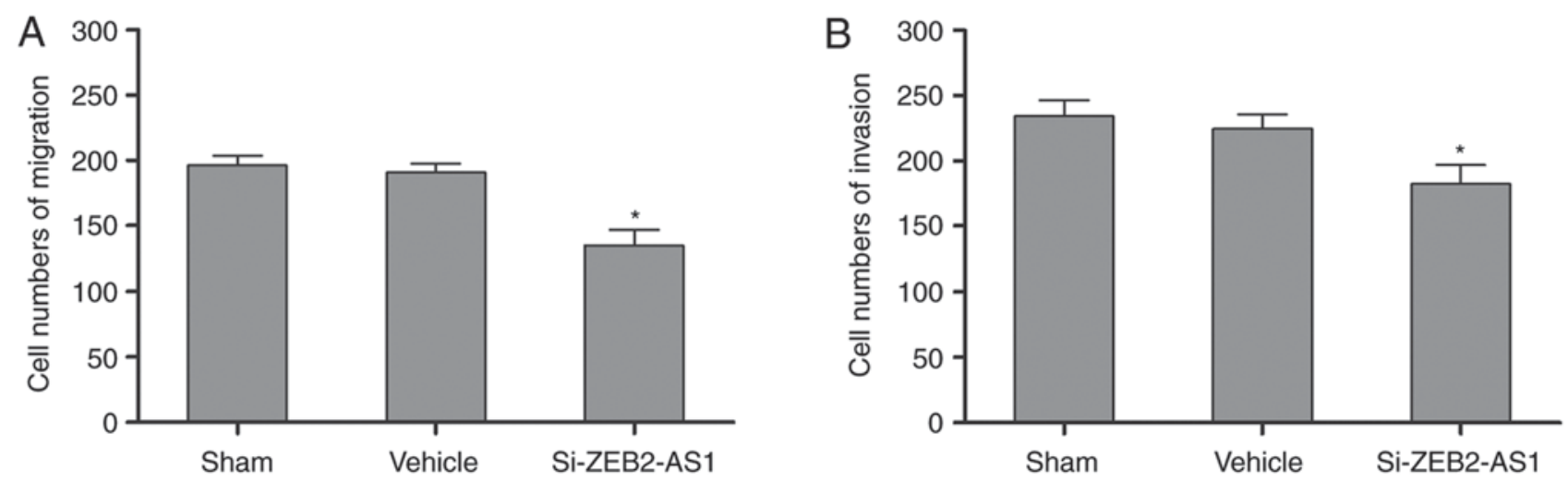

Figure 6. Effects of ZEB2-AS1 lncRNA on the cellular migration and invasion of THP-1 cells. The biological behavior of (A) migration and (B) invasion were significantly inhibited following the knockdown of ZEB2-AS1 lncRNA in THP-1 cells. "P<0.05 vs. Sham and vehicle groups. Values are the mean \pm standard error of the mean. ZEB2-AS1, zinc finger E-box binding homeobox 2 antisense RNA 1; 1ncRNA, long non-coding RNA; si-, small interfering RNA.
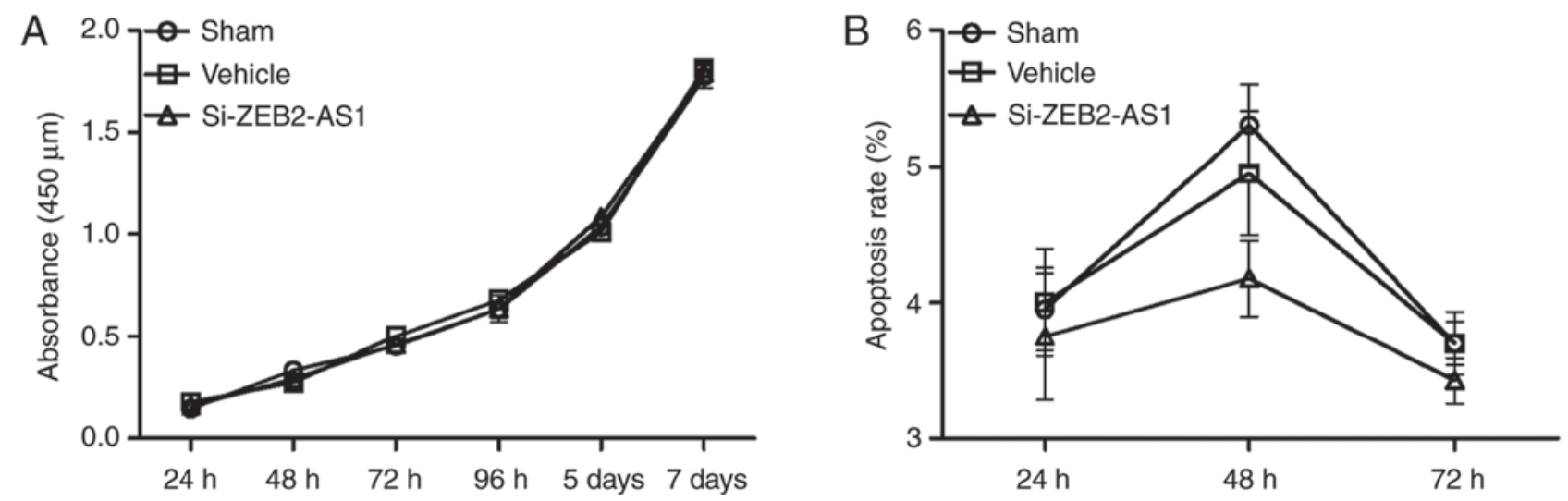

Figure 7. Effects of ZEB2-AS1 lncRNA on cellular proliferation and apoptosis in THP-1 cells. Following the knockdown of ZEB2-AS1 lncRNA, the (A) proliferation and (B) apoptosis exhibited no significant differences in THP-1 cells compared with the sham and vehicle groups. Values are the mean \pm standard error of the mean. ZEB2-AS1, zinc finger E-box binding homeobox 2 antisense RNA 1; lncRNA, long non-coding RNA; si-, small interfering RNA.

\section{Discussion}

In the present study, it was proposed that the abnormal overexpression of ZEB2-AS1 lncRNA may be closely associated with adverse outcomes in patients with AML, and may exert functional roles in regulating biological behaviors. By retrospectively analyzing 62 patients with de novo AML, the present study contributed novel results to the literature, demonstrating that the expression of ZEB2-AS1 1ncRNA was abnormally elevated and may have potential as an epigenetic biomarker 
for evaluating the clinical outcomes of AML. Furthermore, it was revealed that ZEB2-AS1 lncRNA effectively modulated leukemic phenotypes including the invasion and migration of an AML cell line.

The association between ZEB2-AS1 lncRNA expression and a series of clinical features, cytogenetic characteristics, somatic mutations and clinical outcomes in patients with AML was initially investigated. The results revealed that the expression of ZEB2-AS1 lncRNA was significantly higher in the AML group compared with that of a non-malignant group $(\mathrm{P}<0.001$, Fig. 1A). This indicated that the overexpression of ZEB2-AS1 lncRNA may function as a cancer-specific molecular signal in leukemogenesis. With respect to the identified karyotype and recurrent mutations, according to either the modified MRC or ELN risk stratification recommendations (37-39), the expression levels of ZEB2-AS1 lncRNA had a significant stepwise increase from the favorable to adverse risk group (all $\mathrm{P}<0.05$, Fig. $1 \mathrm{~B}$ and $\mathrm{C}$ ). Additionally, the high expression of ZEB2-AS1 lncRNA was associated with adverse patient outcomes compared with the low expression of ZEB2-AS1 lncRNA (Table I). This suggests that the overexpression of ZEB2-AS1 lncRNA is closely associated with a higher risk in AML.

Accumulating evidence has revealed that numerous lncRNAs may independently predict the prognosis for patients with cancer $(23,42-44)$. Notably, previous research has indicated that lncRNAs expression profiles have the potential to independently predict clinical outcomes in AML (21). Novel studies have further demonstrated that, due to its extensive oncogenic functions, the overexpression of HOTAIR IncRNA predicts poor clinical outcomes in AML and may be a potential therapeutic target (25). In the present study, to evaluate the potential of its prognostic application, the impact of ZEB2-AS1 lncRNA overexpression on OS and DFS rates in patients with AML was measured. Univariate analyses revealed that patients with high ZEB2-AS1 lncRNA expression had significantly shorter OS and DFS rates compared with the low ZEB2-AS1 lncRNA expression group (all $\mathrm{P}<0.05$, Table III; Fig. 2). However, using the method of multivariate analyses to control for confounding variables, the adjusted 3-year OS and DFS rates were not significantly different between patients with AML with different expression levels (high vs. low) of ZEB2-AS1 lncRNA (Table IV). Furthermore, it was demonstrated that in the favorable/intermediate risk group, patients with a higher expression of ZEB2-AS1 lncRNA exhibited significantly shorter OS and DFS rates compared with those with a lower expression (all $\mathrm{P}<0.05$, Fig. 3). Therefore, it was proposed that although its independent prognostic value for survival was not rigorously ascertained, the expression levels of ZEB2-AS1 lncRNA may function as a complementary factor to further improve conventional risk stratification models in AML.

Treatment responses in AML are notably heterogeneous and affected by various demographic and biological factors (45-47). To minimize influences of different treatment approaches on clinical outcome interpretation, patients enrolled in the present cohort were treated with an identical induction chemotherapy regimen. It was revealed that the expression levels of ZEB2-AS1 lncRNA were significantly higher in patients who did not achieve initial CR compared with 
those who did $(\mathrm{P}=0.042$, Fig. 1D). In addition, patients with a high expression of ZEB2-AS1 lncRNA had a significantly lower CR rate compared with those with a low expression of ZEB2-AS1 lncRNA ( $\mathrm{P}=0.031$, Table I). This demonstrated that the overexpression of ZEB2-AS1 lncRNA may be closely associated with chemotherapy resistance. Following front-line induction chemotherapy, patients with AML received either consolidation chemotherapy or allo-HSCT. The results revealed that differences between the 3-year OS and DFS rates in the consolidation chemotherapy and allo-HSCT treatment groups were not significantly different (Table III). Furthermore, using stratification to control for confounding variables, patients with low ZEB2-AS1 1ncRNA expression in the allo-HSCT-treated group had a significantly longer OS and DFS compared with that of the chemotherapy group (all $\mathrm{P}<0.05$, Fig. 4). This suggested that patients with AML with a low expression of ZEB2-AS1 lncRNA may be more sensitive to allo-HSCT therapy. In comparison with the relatively static genetic landscape, epigenetic status, including DNA methylation, is altered during different phases of AML (13). However, dynamic changes in ZEB2-AS1 lncRNA expression in this retrospective cohort could not be evaluated, and the association of ZEB2-AS1 lncRNA with treatment responses requires further consolidation by future prospective studies.

The limitations of the present clinical study should be considered carefully. From a clinical point of view, therapeutic strategies for AML have improved in previous years (47). Additionally, cytogenetic/molecular risk stratification systems remain controversial and require further improvement $(7,9,11)$. These all affect the prognostic importance of ZEB2-AS1 lncRNA in AML to varying degrees. Furthermore, from a statistical point of view, the retrospective cohort size in the present study was relatively small, which may have affected the multivariate analysis results. Thus, a future study with a large cohort must be retrospectively and/or prospectively analyzed to further assess the prognostic value of ZEB2-AS1 lncRNA for patient survival and treatment response in AML, independent of various approved clinical factors.

Increasing evidence has demonstrated that various lncRNAs serve essential functions in not only in intrinsic cellular regulatory networks, but also in intercellular communications during tumorigenesis (23). Multiple lncRNAs have been confirmed to function as original drivers and/or downstream targets in circuits involving almost all hallmarks of cancer, including proliferation, viability, immortality, motility, angiogenesis and tumor suppression $(23,48)$. Previously, it has been reported that a natural antisense transcript of ZEB2 may regulate the EMT in different tumor types, including colon adenocarcinoma (35). The highly-conserved zinc-finger structure of ZEB2 binds to E-boxes located in the promoter regions of certain target genes including E-cadherin, so as to further regulate EMT in cancer progression $(49,50)$. Novel results have demonstrated that abnormal expression of ZEB1 may promote cellular proliferation and tumor growth in mantle cell lymphoma (51). Furthermore, ZEB1 expression is controlled by growth arrest specific 5-AS1 lncRNA to modulate cell migration and invasion in non-small cell lung cancer (52). Notably, a novel ZEB2-BAF chromatin remodeling complex subunit BCL11B fusion gene has been identified in patients with AML with karyotype of $t(2 ; 14)(q 22 ; q 32)$, which may be a potential leukemogenic regulator in tumorigenesis (53). In the present study, the results revealed that the knockdown of ZEB2-AS1 lncRNA in THP-1 cells effectively downregulated the mRNA expression of ZEB2 (Fig. 5A), which was consistent with the results of a previous study (35). In addition, the knockdown of ZEB2-AS1 lncRNA in THP-1 cells significantly increased the mRNA expression of E-cadherin compared with the sham/vehicle groups (all $\mathrm{P}<0.05$, Fig. 5B), and the repression of E-cadherin has been demonstrated to trigger the EMT in cancer progression (54). In addition, it was revealed that cellular migration and invasion were significantly inhibited in THP-1 cells following ZEB2-AS1 lncRNA downregulation by si-ZEB2-AS1 (all P<0.05, Fig. 6). However, the knockdown of ZEB2-AS1 lncRNA in THP-1 cells had no apparent effects on proliferation and apoptosis (Fig. 7). Accordingly, it was proposed that ZEB2-AS1 1ncRNA may have upregulated ZEB2 expression, which in turn enhanced the motility phenotype of THP-1 cells, including their invasion and migration abilities in vitro. These results suggested that chemotherapy resistance in patients with a high expression of ZEB2-AS1 lncRNA may be closely associated with enhanced cellular migration and invasion during leukemic progression. This would be consistent with the results of a previous study that demonstrated that ZEB family protein expression may predict differential responses to various chemotherapy drugs in hematopoietic malignancies, including mantle cell lymphoma (51).

In conclusion, to the best of our knowledge, the present study was the first to evaluate the prognostic value of ZEB2-AS1 lncRNA in AML. The results demonstrated that the overexpression of ZEB2-AS1 lncRNA was associated with poor clinical outcomes in AML. Although the independent prognostic prediction for survival was not rigorously researched in the present study, the overexpression of ZEB2-AS1 lncRNA may function as a candidate gene to improve cytogenetic/somatic mutation risk stratification systems in AML. Furthermore, it was discovered that ZEB2-AS1 1ncRNA effectively modulated the leukemic phenotypes of invasion and migration, which may be associated with the differential responses to treatment strategies. Finally, another question must be addressed-why is ZEB2-AS1 lncRNA overexpressed in AML? It was noted that the expression levels of ZEB2-AS1 lncRNA in the AML group exhibit high heterogeneity, with greater variability compared with that of the non-malignant group. Furthermore, in patients with AML with a karyotype of 11q23, ZEB2-AS1 lncRNA expression was notably high. AML pathogenesis with a 11q23 karyotype involves the abnormal rearrangement of the mixed lineage leukemia gene, which is an epigenetic modifier involved in histone methylation (55). It was hypothesized that the overexpression of ZEB2-AS1 lncRNA may not be a key event during leukemogenesis, but a downstream target of other key oncogenic events. As previously mentioned, the expression profiling of lncRNAs is able to independently evaluate survival in older patients with cytogenetically normal AML (21). A novel study revealed that the combination of $>1$ lncRNA (i.e. a six-lncRNA signature) may be strongly associated with survival in diffuse large B-cell lymphoma (44). This suggests that one lncRNA alone may be not sufficient in independently predicting the survival of patients with AML. These key problems require thorough investigation in the future. 


\section{Acknowledgements}

Not applicable.

\section{Funding}

This work was supported by the Priority Academic Program Development of Jiangsu Higher Education Institutions, the National Clinical Key Subject Project, the Innovation Capability Development Project of Jiangsu Province (grant no. BM2015004), the Natural Science Foundation of China (grant nos. 81570139 and 81270617), the Jiangsu Provincial Special Program of Medical Science (grant no. BL2012005), Jiangsu Province's Key Medical Center (grant no. ZX201102), the Jiangsu Province Natural Science Fund (grant no. BE2015639), the Project of Natural Science Foundation of Jiangsu Province (grant no. BK20141201) and the National Natural Science Foundation of China Youth Fund Project (grant no. 81300424).

\section{Availability of data and materials}

The datasets used and analyzed during the current study are available from the corresponding author on reasonable request.

\section{Authors' contributions}

XS finished all the experiments, analyzed and interpreted the patient data, and was a major contributor in writing the manuscript. JL finished most of the experiments. LM, LW, QW and HY performed some experiments. CR and DW had substantial contributions to the conception and design of the work. XZ and SC designed the study and took final responsibility. All authors read and approved the final manuscript.

\section{Ethics approval and consent to participate}

The present study was approved by the Institutional Review Board of the First Affiliated Hospital of Soochow University Written informed consent was obtained from all participants for the use of bone marrow specimens and clinical information.

\section{Patient consent for publication}

Not applicable.

\section{Competing interests}

The authors declare that they have no competing interests.

\section{References}

1. Döhner H, Weisdorf DJ and Bloomfield CD: Acute myeloid leukemia. N Engl J Med 373: 1136-1152, 2015.

2. Polednak AP: Recent improvement in completeness of incidence data on acute myeloid leukemia in US cancer registries. J Registry Manag 41: 77-84, 2014.

3. Tawfik B, Pardee TS, Isom S, Sliesoraitis S, Winter A, Lawrence J, Powell BL and Klepin HD: Comorbidity, age, and mortality among adults treated intensively for acute myeloid leukemia(AML).JGeriatr Oncol 7: 24-31, 2016
4. Almeida AM and Ramos F: Acute myeloid leukemia in the older adults. Leuk Res Rep 6: 1-7, 2016.

5. Percival ME, Tao L, Medeiros BC and Clarke CA: Improvements in the early death rate among 9,380 patients with acute myeloid leukemia after initial therapy: A SEER database analysis. Cancer 121: 2004-2012, 2015.

6. Bhatnagar B and Garzon R: The use of molecular genetics to refine prognosis in acute myeloid leukemia. Curr Hematol Malig Rep 9: 148-157, 2014.

7. Stölzel F, Mohr B, Kramer M, Oelschlägel U, Bochtler T, Berdel WE, Kaufmann M, Baldus CD, Schäfer-Eckart K, Stuhlmann R, et al: Karyotype complexity and prognosis in acute myeloid leukemia. Blood Cancer J 6: e386, 2016.

8. Mrózek K and Bloomfield CD: Chromosome aberrations, gene mutations and expression changes, and prognosis in adult acute myeloid leukemia. Hematology Am Soc Hematol Educ Program 2006: 169-177, 2006.

9. Papaemmanuil E, Gerstung M, Bullinger L, Gaidzik VI, Paschka P, Roberts ND, Potter NE, Heuser M, Thol F, Bolli N, et al: Genomic classification and prognosis in acute myeloid leukemia. N Engl J Med 374: 2209-2221, 2016.

10. Byun JM, Kim YJ, Yoon HJ, Kim SY, Kim HJ, Yoon J, Min YH, Cheong JW, Park J, Lee JH, et al: Cytogenetic profiles of 2,806 patients with acute myeloid leukemia-a retrospective multicenter nationwide study. Ann Hematol 95: 1223-1232, 2016.

11. Li S, Mason CE and Melnick A: Genetic and epigenetic heterogeneity in acute myeloid leukemia. Curr Opin Genet Dev 36: 100-106, 2016

12. Cancer Genome Atlas Research Network, Ley TJ, Miller C, Ding L, Raphael BJ, Mungall AJ, Robertson A, Hoadley K, Triche TJ Jr, Laird PW, et al: Genomic and epigenomic landscapes of adult de novo acute myeloid leukemia. N Engl J Med 368: 2059-2074, 2013.

13. Li S, Garrett-Bakelman FE, Chung SS, Sanders MA, Hricik T, Rapaport F, Patel J, Dillon R, Vijay P, Brown AL, et al: Distinct evolution and dynamics of epigenetic and genetic heterogeneity in acute myeloid leukemia. Nat Med 22: 792-799, 2016

14. Sasca D and Huntly BJ: Independence of epigenetic and genetic diversity in AML. Nat Med 22: 708-709, 2016.

15. Mattick JS and Makunin IV: Non-coding RNA. Hum Mol Genet 15 Spec No 1: R17-R29, 2006.

16. Morris KV and Mattick JS: The rise of regulatory RNA. Nat Rev Genet 15: 423-437, 2014.

17. Djebali S, Davis CA, Merkel A, Dobin A, Lassmann T, Mortazavi A, Tanzer A, Lagarde J, Lin W, Schlesinger F, et al: Landscape of transcription in human cells. Nature 489: 101-108, 2012.

18. Iyer MK, Niknafs YS, Malik R, Singhal U, Sahu A, Hosono Y, Barrette TR, Prensner JR, Evans JR, Zhao S, et al: The landscape of long noncoding RNAs in the human transcriptome. Nat Genet 47: 199-208, 2015.

19. Goff LA and Rinn JL: Linking RNA biology to lncRNAs. Genome Res 25: 1456-1465, 2015.

20. Ling H, Vincent K, Pichler M, Fodde R, Berindan-Neagoe I, Slack FJ and Calin GA: Junk DNA and the long non-coding RNA twist in cancer genetics. Oncogene 34: 5003-5011, 2015.

21. Garzon R, Volinia S, Papaioannou D, Nicolet D, Kohlschmidt J, Yan PS, Mrózek K, Bucci D, Carroll AJ, Baer MR, et al: Expression and prognostic impact of lncRNAs in acute myeloid leukemia. Proc Natl Acad Sci USA 111: 18679-18684, 2014.

22. Morlando M, Ballarino $M$ and Fatica A: Long non-coding RNAs: New players in hematopoiesis and leukemia. Front Med (Lausanne) 2: 23, 2015.

23. Schmitt AM and Chang HY: Long noncoding RNAs in cancer pathways. Cancer Cell 29: 452-463, 2016.

24. Zhang X, Lian Z, Padden C, Gerstein MB, Rozowsky J, Snyder M, Gingeras TR, Kapranov P, Weissman SM and Newburger PE: A myelopoiesis-associated regulatory intergenic noncoding RNA transcript within the human HOXA cluster. Blood 113: 2526-2534, 2009.

25. Xing CY, Hu XQ, Xie FY, Yu ZJ, Li HY, Bin-Zhou, Wu JB, Tang LY and Gao SM: Long non-coding RNA HOTAIR modulates c-KIT expression through sponging miR-193a in acute myeloid leukemia. FEBS Lett 589: 1981-1987, 2015.

26. Ma L, Bajic VB and Zhang Z: On the classification of long non-coding RNAs. RNA Biol 10: 925-933, 2013. 
27. Mattick JS and Rinn JL: Discovery and annotation of long noncoding RNAs. Nat Struct Mol Biol 22: 5-7, 2015.

28. Khorkova O, Myers AJ, Hsiao J and Wahlestedt C: Natural antisense transcripts. Hum Mol Genet 23: R54-R63, 2014.

29. Katayama S, Tomaru Y, Kasukawa T, Waki K, Nakanishi M, Nakamura M, Nishida H, Yap CC, Suzuki M, Kawai J, et al: Antisense transcription in the mammalian transcriptome. Science 309: 1564-1566, 2005.

30. ENCODE Project Consortium. An integrated encyclopedia of DNA elements in the human genome. Nature 489: 57-74, 2012.

31. Su WY, Xiong H and Fang JY: Natural antisense transcripts regulate gene expression in an epigenetic manner. Biochem Biophys Res Commun 396: 177-181, 2010.

32. Wight $M$ and Werner A: The functions of natural antisense transcripts. Essays Biochem 54: 91-101, 2013.

33. Ebralidze AK, Guibal FC, Steidl U, Zhang P, Lee S, Bartholdy B, Jorda MA, Petkova V, Rosenbauer F, Huang G, et al: PU.1 expression is modulated by the balance of functional sense and antisense RNAs regulated by a shared cis-regulatory element. Genes Dev 22: 2085-2092, 2008.

34. Sun J, Li W, Sun Y, Yu D, Wen X, Wang H, Cui J, Wang G, Hoffman AR and Hu JF: A novel antisense long noncoding RNA within the IGF1R gene locus is imprinted in hematopoietic malignancies. Nucleic Acids Res 42: 9588-9601, 2014

35. Beltran M, Puig I, Peña C, García JM, Alvarez AB, Peña R, Bonilla $\mathrm{F}$ and de Herreros AG: A natural antisense transcript regulates Zeb2/Sip1 gene expression during Snail1-induced epithelial-mesenchymal transition. Genes Dev 22: 756-769, 2008.

36. Arber DA, Orazi A, Hasserjian R, Thiele J, Borowitz MJ, Le Beau MM, Bloomfield CD, Cazzola M and Vardiman JW: The 2016 revision to the World Health Organization classification of myeloid neoplasms and acute leukemia. Blood 127: 2391-2405, 2016.

37. Metzeler KH, Herold T, Rothenberg-Thurley M, Amler S, Sauerland MC, Görlich D, Schneider S, Konstandin NP, Dufour A, Bräundl K, et al: Spectrum and prognostic relevance of driver gene mutations in acute myeloid leukemia. Blood 128 : 686-698, 2016

38. Grimwade D, Hills RK, Moorman AV, Walker H, Chatters S, Goldstone AH, Wheatley K, Harrison CJ and Burnett AK National Cancer Research Institute Adult Leukaemia Working Group: Refinement of cytogenetic classification in acute myeloid leukemia: Determination of prognostic significance of rare recurring chromosomal abnormalities among 5876 younger adult patients treated in the United Kingdom Medical Research Council trials. Blood 116: 354-365, 2010.

39. Röllig C, Bornhäuser M, Thiede C, Taube F, Kramer M, Mohr B, Aulitzky W, Bodenstein H, Tischler HJ, Stuhlmann R, et al: Long-term prognosis of acute myeloid leukemia according to the new genetic risk classification of the European LeukemiaNet recommendations: Evaluation of the proposed reporting system. J Clin Oncol 29: 2758-2765, 2011.

40. McGowan-Jordan J, Simons A and Schmid M (eds): An International System for Human Cytogenomic Nomenclature (2016). Cytogenetic and Genome Research 149: No. 1-2, 2016.
41. Livak KJ and Schmittgen TD: Analysis of relative gene expression data using real-time quantitative PCR and the 2(-Delta Delta C(T)) method. Methods 25: 402-408, 2001.

42. Wang KC and Chang HY: Molecular mechanisms of long noncoding RNAs. Mol Cell 43: 904-914, 2011.

43. Bhan A and Mandal SS: lncRNA HOTAIR: A master regulator of chromatin dynamics and cancer. Biochim Biophys Acta 1856: 151-164, 2015.

44. Sun J, Cheng L, Shi H, Zhang Z, Zhao H, Wang Z and Zhou M: A potential panel of six-long non-coding RNA signature to improve survival prediction of diffuse large-B-cell lymphoma. Sci Rep 6: 27842, 2016

45. Schlenk RF, Dohner K, Krauter J, Fröhling S, Corbacioglu A, Bullinger L, Habdank M, Späth D, Morgan M, Benner A, et al: Mutations and treatment outcome in cytogenetically normal acute myeloid leukemia. N Engl J Med 358: 1909-1918, 2008.

46. Xu Y, Sun Y, Shen H, Ding L, Yang Z, Qiu H, Sun A, Chen S and Wu D: Allogeneic hematopoietic stem cell transplantation could improve survival of cytogenetically normal adult acute myeloid leukemia patients with DNMT3A mutations. Am J Hematol 90: 992-997, 2015

47. Dombret $\mathrm{H}$ and Gardin C: An update of current treatments for adult acute myeloid leukemia. Blood 127: 53-61, 2016.

48. Hanahan D and Weinberg RA: Hallmarks of cancer: The next generation. Cell 144: 646-674, 2011

49. Vandewalle C, Van Roy F and Berx G: The role of the ZEB family of transcription factors in development and disease. Cell Mol Life Sci 66: 773-787, 2009.

50. Hill L, Browne $\mathrm{G}$ and Tulchinsky E: ZEB/miR-200 feedback loop: At the crossroads of signal transduction in cancer. Int J Cancer 132: 745-754, 2013.

51. Sánchez-Tilló E, Fanlo L, Siles L, Montes-Moreno S, Moros A, Chiva-Blanch G, Estruch R, Martinez A, Colomer D, Gyórffy $\mathrm{B}$, et al: The EMT activator ZEB1 promotes tumor grow th and determines differential response to chemotherapy in mantle cell lymphoma. Cell Death Differ 21: 247-257, 2014

52. Wu Y, Lyu H, Liu H, Shi X, Song Y and Liu B: Downregulation of the long noncoding RNA GAS5-AS1 contributes to tumor metastasis in non-small cell lung cancer. Sci Rep 6: 31093, 2016.

53. Torkildsen S, Gorunova L, Beiske K, Tjonnfjord GE, Heim S and Panagopoulos I: Novel ZEB2-BCL11B fusion gene identified by RNA-sequencing in acute myeloid leukemia with $\mathrm{t}(2 ; 14)$ (q22; 32). PLoS One 10: e0132736, 2015.

54. Schmalhofer O, Brabletz S and Brabletz T: E-cadherin, beta-catenin, and ZEB1 in malignant progression of cancer. Cancer Metastasis Rev 28: 151-166, 2009.

55. Stein EM and Tallman MS: Mixed lineage rearranged leukaemia: Pathogenesis and targeting DOT1L. Curr Opin Hematol 22: 92-96, 2015.

This work is licensed under a Creative Commons Attribution-NonCommercial-NoDerivatives 4.0 International (CC BY-NC-ND 4.0) License. 